\title{
Impact of COST 271
}

\author{
PETER A. BRADLEY ( $\left.{ }^{(}\right)$and BODO W. REINISCH ( $\left.{ }^{2}\right)$ \\ (') Pandora, Scotlands Drive, Farnham Common, Slough, Berks, U.K. \\ $\left({ }^{2}\right)$ Environmental, Earth, and Atmospheric Sciences Department, Center for Atmospheric Research, \\ University of Massachusetts, Lowell, MA, U.S.A.
}

This article discusses the significance of the achievements of the COST 271 Action on science and technology for space weather and telecommunications in Europe and the world. The Action's work has impacted national and international projects and the decision processes. The key words encompassed in the title of COST 271 are «space weather». But as the reader of this Final Report will appreciate, many more topics were addressed during the Action by the large team of workers from a wide range of countries and organisations than this wording would suggest. Relevant to the performance of telecommunication systems that rely on the presence of the ionosphere for propagation support, or that are affected by transmission through it, there have been investigations among other items of solar and magnetosphere disturbances on the ionosphere, satellite and ground-based measurements of the ionosphere, assembly of near-real-time databases of ionosphere information on the Web, studies of planetary and gravity waves in the ionosphere, ionosphere modelling, mapping and forecasting, long-term changes, ray-path deviations in the presence of irregularities, channel-scattering functions, and scintillations on Earth-space paths. The impact of all this work on the outside communities can be considered within three broad headings as follows.

\section{The Final Report AND PUblished MATERIAL}

The Final Report by its limited size has to be, of necessity, restrictive of content, and to include just a selection of topics with only brief comments for each. In some senses then it serves rather like an encyclopaedia giving a range of headings, where the reader is referred elsewhere for the fuller stories. Indeed an extensive series of lists of references are included, and it is in the details of these that much information on what has been done may be obtained. Throughout the lifetime of COST 271 there have been, as previously noted in the Report, three very successful Workshops with specific themes, at which in total 172 papers were presented. The written versions of these papers appear on two CD's plus a dedicated Web site. There have too been a number of stand-alone papers tabled at Management Committee meetings. There is also an impressive list of single-topic papers presented at multi-nation conferences and published in established peer-reviewed international journals. The body of all this information, considered collectively, can be regarded as a legitimate product of COST 271 achievements.

With so much information it is understandable that there is no single body or organisation as the natural recipient of these results. On the one hand there are international groups that can benefit from COST 271 findings as discussed below. There are also individuals and single radio-user organisations that may find solutions to their problems of the moment in the texts of COST 271. Undoubtedly this Final Report is a first step in learning what has been done and is available, but these reviewers feel that consideration should be given to making this information more generally available through a wider publicity medium, probably via a permanent general access web-based source. This is most likely a problem encountered by all completing COST Actions that should be addressed on a Commission basis. 
Nevertheless, throughout the lifetime of the Action the Management Committee has been conscious to ensure the greatest liaison with those outside groups that can best take account of the work accomplished. The Chairman and Vice-Chair have taken every opportunity to publicise and draw attention to COST 271 activities at many relevant and related meetings of outside bodies. The Action has been fortunate in including among its membership a number of key-players who hold office posts within other groups, and this has helped in a two-way synergy in passing on products, in learning of requirements and in obtaining suggestions from the international community at large for the studies necessary for the solution of the problems of the day.

An obvious benefactor of COST 271 results is the International Telecommunication Union (ITU), which body serves the role of laying down standards for the operation of the world's telecommunication systems, with in particular its Radiocommunication Sector (ITU-R) examining technical aspects of radio systems and making Recommendations to the ITU on best engineering practises for radio-service planning. Specifically the work of COST 271 falls almost entirely within the area of Study Group 3 (Propagation in Ionised Media) of the ITU-R. The Study Groups of the ITU-R, consisting of National Delegates from Member Countries, meet periodically to consider formal proposals for additions or amendments to Standing Texts. COST 271 has been fortunate in that several of its participants have served as National Delegates, thereby providing an avenue for the transmittal of products and the presentation and discussion of these at the appropriate meetings. Of particular mention are the submission and adoption, with associated computer programs being maintained by the ITU-R Secretariat, of the median electron-density model height profile NeQuick for the determination by integration of the associated total electron content, and the scintillation model GISM, generated under ESA auspices but with COST 271 involvement, for estimating scintillation amplitude and phase fluctuations on Earth-space paths. At the same time COST 271 has been made aware of ITU needs through the standing formal Questions of the ITU-R.

The International Union of Radio Science (URSI) does not have a direct role in the control of radio usage, but through its periodic General Assemblies and ongoing Working Groups that both correspond informally and hold occasional limited-agenda meetings, it is able to address some of the topics of an intricate and perhaps more scientific element that cannot be considered within the formal nature of ITU-R sessions. Commission G of URSI has as its remit «Ionosphere Radio and Propagation». Several COST 271 participants are or have been Office Holders of URSI Working Groups and have attended Assemblies and Group Meetings. URSI is a formal Member of the ITU and COST 271 participants have served on a special joint URSI-ITU Scientific Committee on Telecommunications with the goals of seeking to steer the URSI studies to address the ITU needs and to ensure that the relevant outcomes of URSI activities are transmitted to the ITU. It has to be admitted that, admirable though the goals of this committee are and the enthusiasm of its members, the outcomes have not been entirely successful, a matter of some concern to the URSI Boards. The involvement of COST 271 within URSI has been quite positive, and the interchange of ideas with the wider scientific community fruitful in both directions.

A separate organisation, but also operating like URSI as a loose grouping of primarily un-sponsored scientists within the umbrella of the International Council of Scientific Unions (ICSU), is the Committee on Space Research (COSPAR). This addresses all aspects of research within the area of the Earth's environment, the neighbourhood of other planets and within outer space. Its Commission $\mathrm{C}$ has the remit: «Space studies of the upper atmospheres of the Earth and planets, including reference atmospheres», and it also has a «Panel on Space Weather». COST 271 participants take part and present results to General Assemblies of the COSPAR. A joint COSPAR Commission C-URSI standing organisation is the International Reference Ionosphere (IRI), and COST 271 participants are actively involved as members of this group. The IRI is concerned with producing reference models to define on a worldwide basis the geographical and temporal variations of the height distributions of electron density, ion composition, temperatures, and drifts. The IRI holds a wide number of meetings as it seeks to extend and refine its models in the light of the latest observational data. A number of 
COST 271 participants are also members of the IRI, where for them the greatest interest lies in the electron density component, with particularly the determination of Total Electron Content (TEC), which is the height-integrated profile. COST 271 has made a major impact in the specification of the topside model above the height of peak electron density, which is responsible for much of the contribution to total electron content, and so to ionosphere influences on Earth-space radio propagation. Besides attendance at these international meetings, COST 271 participants have hosted such meetings including an annual event at the Abdus Salam International Centre for Theoretical Physics in Trieste where in recent years attention has been paid to the quantification and specification of ionosphere variability. The IRI model has also been forwarded to the ITU-R. One of the authors of this review is the chairman of IRI and thankfully acknowledges the helpful consultation the COST 271 Action provided for the definition of the IRI ionosphere-plasmasphere electron density distribution.

There are a range of other regional and international organisations that address specific topics through their periodic meetings that encompass aspects within the purview of COST 271, and where its participants have made significant contributions to proceedings. We specifically like to mention the annual European Geophysical Society (now Union) meetings, where sessions have been convened by the COST 271 Chairman, with wide attendance of other COST 271 participants. Critical Action issues were thus presented to a broad scientific audience inviting critique and inputs. Mention should be made too of links with the Northern European Incoherent SCATter facility (EISCAT), data from which have been valuable to the studies conducted within the Action. There are other limited-agenda conferences organised on an ad-hoc basis in which COST 271 participants have taken the lead and provided the hosting logistics. In all this work the name of COST 271 and the range of its studies have received wide recognition and respect within the international scientific community.

There is no doubt that propagation plays a vital role in controlling the ultimate performance characteristics of radio systems. The evolution of ever-more sophisticated navigation, communications and surveillance systems calls for data needs to planning and operation that do not currently exist, or can even be envisaged at the present time. Traditionally where radio planners identify a requirement that cannot be met with current information, they establish specific groups to address the topics in hand. Particular examples are where proposals for changes in broadcast planning have been formulated via regional groupings such as the European Broadcasting Union (EBU), or the equivalents in other parts of the world like the Asia Pacific Broadcasting Union (ABU) and the Inter-American Association of Broadcasters (AIR). The same applies within other disciplines, as for example space navigation with the ESA initiatives noted above. But such groups are short-lived, have a particular remit, and are disbanded when they have met their target goals. We know of no other co-ordinated regional groupings like COST 271 and its former Actions to have been established in North and South America, Asia, the Far East, or Australia and to have maintained a continuity of existence, in the case of COST for more than a decade, to provide an ongoing forum and level of expertise of state-of-the art in ionosphere studies. The wealth of information about the ionosphere that has been derived over nearly a century cannot be learned over-night and it is important that this information is not lost, lest it fail to be applied to ongoing problems that arise. In some senses it can be argued that to maintain this general level of expertise is more important than the precise work of the moment that is carried out, and it is encouraging to note the numbers of young workers who have participated in this Action in recent years. The ionosphere knows no geographical bounds and it is important to Europe that there should be a co-ordinated group that can be called upon to formulate and defend proposals that affect the whole world when an independent need is identified.

\section{ACTIVITIES WITHIN HOST ORGANISATIONS}

COST is a framework for European collaborations within areas specified within the Memorandum of Understanding of each Action and the level of support provided by the Commission is primarily limited to secretarial and meeting expenses. Funding of the work carried out by individual participants is 
the responsibility of employer organisations. In principle a conflict could arise where the needs of those organisations differ from what activities the Management Committee decides to carry out. In the case of COST 271 though this problem has never arisen, with individuals selecting those Work Packages to join where the objectives most closely match their stated needs. Good examples are WP 1.2 for the creation of a space-weather database and for now-casting and forecasting propagation conditions, and WP 2.1 for the investigation of plasma effects on Global Navigation Satellite System (GNSS) applications, particularly by using the radio-occultation technique in conjunction with Low Earth-Orbiting satellites (LEOs) to study vertical ionosphere structure. Inevitably, there has been some adapting of the work in certain cases to bring these into line as the studies have progressed, and inevitably too there have been a few topics initially conceived as to be investigated which have not been addressed, e.g., to gain better knowledge of effects of noise and interference on terrestrial communications. This is seen as a natural consequence of the COST framework and is here of only minor significance.

Unlike some Actions, participants in COST 271 have been drawn mainly from universities and government-sponsored organisations in the separate countries, with only limited industrial involvement. It is not then possible to quantify how valuable the COST 271 work has been to each of these organisations, or to the wider interests of the numerous other organisations within their separate countries that these groups in turn serve. To determine this information would require an in-depth survey that would probably be very difficult to conduct. What can be cited though is that COST 271 is a natural successor of former Actions COST 238 and COST 251 with many participants common to all three Actions. Their continued presence can be seen as justification of the value their sponsors place on this work. On the other hand we notice that more than 20 young scientists, both female and male, have joined the Action from a range of countries including Spain, Italy, United Kingdom, Czech Republic, and Greece. The important role women play in science and engineering in Europe is reflected in the large number of female active participants in COST 271.

Besides the specific Work Package achievements, mention should also be made to the valuable synergy that has undoubtedly resulted for all those involved. Teams have been assembled to tackle jobs that were too extensive for single organisations to embark upon, the opportunities to meet scientists and engineers from other countries with like interests but differing ideas, and the value of informed opinions of topics to pursue, particularly in the case of those working in isolation within their organisations or without wide background experience, must have been considerable.

\section{Collaborative ParTnERShIPS IN OTHER INITIATIVES}

Throughout the duration of COST 271 participants have become aware, in some cases without having prior knowledge, of other groups in other countries with the same interests, complementary resources and levels of expertise. This has led to a number of bilateral and multi-national collaborations that most probably would not have taken place without the existence of COST 271 and the former two ionosphere COST Actions. These collaborations have undoubtedly been strengthened by the Short-Term Missions initiatives, which have enabled participants from one organisation to work for a short time alongside colleagues in the host organisation on common limited-objective tasks. At the same time to see the peripheral work in progress, the teams involved, aspirations and future goals are strong incentives for extended common activities. Such collaborations are not specifically mentioned within COST 271 publications, but there are a good number of these. Joint Italian-Greek organised meetings in Crete can be cited. Other Bulgarian-Belgium, U.K.-Serbia, Russia-Poland, GermanyGreece, U.K.-France, U.K.-Russia, U.K.-Greece, Turkey-Italy and Spain-Italy collaborations either already have or are continuing to take place.

Management Committee Meetings have always included an agenda item for those present to be made aware of forthcoming meetings and opportunities for future collaborations. Undoubtedly the subject of space-weather is important within a range of disciplines, and it is timely that many COST 
271 participants have also joined the new companion Action COST 724: «Space Weather Applications and Services», for which the Vice Chairperson is also a Work Package leader in COST 271. Others have associated themselves with the European Space Agency's exploratory navigational satellite system initiative EGNOS as part of the GALILEO research project. COST 271 participants are actively involved in the new initiative ESTAR (European Solar-Terrestrial and Atmospheric Research) proposed to the European Science Foundation to investigate the contributions of the sun to long-term global climate change. All these initiatives benefit from the existence of COST 271, even if that benefit is hard to quantify.

\section{SumMary}

It is hoped this short article will serve to confirm that the contributions from Action COST 271 are considerable. They cannot be measured solely in terms of the contents of this Final Report, nor by the extensive number of publications that have ensued during the project lifetime. Besides the formal contributions to ITU-R and the contributions to international organisations such as URSI and COSPAR, COST 271 has provided materials that it would be hard to quantify to participants' host organisations by way of both consultancy and final products. It has provided a forum for the establishment of collaborative European initiatives, a centre of expertise in ionosphere knowledge when none other equivalent in Europe or elsewhere exists, and a motivation for the continuation and the longterm archiving of synoptic soundings of the state of the ionosphere.

It seems entirely unthinkable to allow the team of experts that composes the COST 271 Action to dissolve after the successful completion of the Action. The continuation into the future of such a group of dedicated workers is highly desirable and will assure success in the work that needs to be done next: development of mitigation techniques. 